\title{
Setor educacional do MERCOSUL: convergência e integração regional da educação superior brasileira ${ }^{1}$
}

\author{
Zuleide S. Silveira
}

Resumo: Este trabalho busca apreender as recentes modificações na educação superior brasileira por meio de duas mediações principais: o Estado brasileiro e o Setor Educacional do Mercado Comum do Sul (SEM). O contexto é de internacionalização da economia e de relações sociopolíticas que consistem nas formas históricas de estruturas articuladas institucionalmente na organização e funcionamento da educação. Evidencia os esforços de gestão supranacional dos assuntos educacionais ao mesmo tempo em que procura compreender a relação entre a grande política (formulada em nível supranacional no SEM) e a pequena política, levada adiante no aparelho de Estado brasileiro, em tono da formulação das políticas públicas de educação superior. Desvela os mecanismos institucionais que vêm propiciando a integração e regionalização da educação superior por meio de dois vetores direcionadores da reforma da educação superior: avaliação e mobilidade. O tempo da pesquisa remonta à gênese do MERCOSUL, no início dos anos 1990, estendendo-se até os dias atuais, com base na análise documental de atas de reuniões, protocolos, planos de ação, tratados e acordos firmados no âmbito do SEM e pelo conjunto de indicações e de legislação formuladas nos mandatos de governos brasileiros, no período 1995-2014, de modo a acrescentar a dimensão do tempo à compreensão da ação política dos sujeitos envolvidos na formulação das políticas de educação superior em âmbito regional e nacional; e, à apreensão dos embates de forças com disputas teóricas e políticas em torno da reforma da educação superior.

Palavras-chave: Setor educacional do MERCOSUL. Integração regional. Políticas de educação superior.

\section{Educational sector of MERCOSUR: convergence and regional integration of brazilian higher education}

Abstract: This work seeks to seize the recent modifications in Brazilian higher education through two main mediations: the Brazilian State and the Educational Sector of Common Market of South (SEM). The context is in which internationalization of economy occurs and socio-political relations that consist of the historical forms of institutionally articulated structures in the organization and functioning of education. It highlights the efforts of supranational management educational affairs at the same time that seeks to understand the relationship between the major policy (formulated in supranational level in SEM) and the small politics, led the Brazilian State, in the formulation of public policies about higher education. It unveils the institutional mechanisms that have been providing integration and regionalization of higher education through two vectors drivers of reform of higher education: evaluation and mobility. The time of research dates back to genesis of MERCOSUR, in the early 1990, extending to the present day, based on documentary analysis of minutes of meetings, action plans, protocols, treaties and agreements signed within the framework of SEM and the set of nominations and legislation formulated in terms of Brazilians governments, in the period 1995-2014, in order to add the dimension of time to understanding the political action of the subjects involved in the formulation of policies on higher education in regional and national levels; and, the seizure of the clashes of forces with theoretical and political disputes around the reform of higher education.

Key words: Educational sector of MERCOSUR. Regional integration. Higher education policies.

1 Este texto tem por base Silveira (2011), do que uma versão foi apresentada no GT 9 (Trabalho e Educação) da 35ª Reunião Anual da ANPEd, realizada em Porto de Galinhas, de 21 a 24 de outubro de 2012. 


\section{Introdução}

As três dimensões fundamentais do capital - produção, consumo e circulação/distribuição/realização - tendem a se fortalecer e a se ampliar por meio da internacionalização da economia/tecnologia, operando nas contradições entre imperialismo e dependência ${ }^{2}$ " "até mesmo em condições extremamente severas de crise estrutural” (MÉSZÁROS, 2006, p. 796-7).

Esta dinâmica capitalista requer estabilidade e previsibilidade institucional, econômica e societária, o que tem implicações na formulação e métodos da ação governamental no âmbito do sistema político-administrativo nacional (DREIFUSS, 1997, 2004; MÉSZÁROS, 2003).

O projeto estadunidense de reconstrução e regulação do capitalismo internacional, a partir do final da Segunda Grande Guerra, bem evidencia a lógica tendencial daquela dinâmica em sua fase imperialista: acentuar as estratégias geopolíticas, diplomáticas e militares usadas por um Estado ou bloco de Estados, em meio à luta para afirmar seus interesses e atingir suas metas rumo ao mundo globalizado.

Promovem-se as conferências de Bretton Woods e cria-se a Organização do Atlântico Norte $(\mathrm{OTAN})^{3}$, precursoras do Plano Marshall para a reconstrução da Europa, que veio a ser executada pela Organização para a Cooperação e Desenvolvimento Econômico (OCDE). Constroem-se uma complexa rede de instituições, agrupadas em três setores, de modo a obter a estabilidade e previsibilidade institucional apontada por Dreifuss (DREIFUSS, 1997; 2004; MÉSZÀROS, 2003).

O primeiro setor, formado pelo Fundo Monetário Internacional, pelo Banco Internacional para Reconstrução e o Desenvolvimento (BIRD) e pelo Acordo Geral sobre Tarifas e Comércio (GATT) ${ }^{4}$, ficou responsável pela supervisão

2 Toma-se por base, aqui, a teoria marxista da dependência que aceita a possibilidade do desenvolvimento capitalista na periferia, enfatizando, porém, a forma dependente, associada e subalterna que o empresariado local/brasileiro adota em relação ao capitalismo central. Ancorada em conceitos como modo de produção, divisão internacional do trabalho, superexploração do trabalho, mercado mundial, lucro, acumulação de capital, monopólio e concorrência, imperialismo e subimperialismo, atraso e subdesenvolvimento, a teoria marxista da dependência contribui para o entendimento de questões como: a expansão do capital em escala global, os processos de integração e regionalização, a extensão da lei do valor e da superexploração do trabalho como mecanismos de compensação das desigualdades que acarretam a superprodução e superacumulação do capital no contexto de organização flexível do trabalho.

3 Do inglês North Atlantic Treaty Organization (NATO).

4 O GATT foi substituído, no ano de 1995, pela Organização Mundial do Comércio (OMC). Na sequencia da criação da OMC foi assinado o Acordo Geral sobre Comércio e Serviços (GATS). A título de esclarecimento: para o GATS, o setor de serviços educacionais abrange educação "primária", "secundária", "pós-secundária", e "terciária", além da educação profissional e da educação de jovens e adultos. Tendo como objetivo principal diminuir as barreiras comerciais, que no caso dos serviços educacionais podem estar associadas aos subsídios dos governos ao setor, à importação de material escolar, à necessidade de vistos, reconhecimento e revalidação de diplomas, aos obstáculos e ou exigências no processo de 
do comércio e do equilíbrio de balanços de pagamentos dos países membros; o segundo constituiu-se da rede global de suas bases militares legitimadas por vários pactos regionais de segurança coletiva ou de defesa bilateral; e, por último, a Organização das Nações Unidas (ONU), com o Conselho de Segurança, responsável pela administração política de conflitos interestatais e a Organização das Nações Unidas para a Educação, Ciência e Cultura (UNESCO), organismo consultor técnico para assuntos de educação, ciência e cultura.

Trata-se, pois, de uma garantia do pleno desenvolvimento capitalista que se dá por mediação do "grande Estado burguês supranacional" (GRAMSCI, 1976, p. $187 ; 2007$, p. 24; 80; 151), cujo poder privado reúne ministros e secretários de Estado, empresários, engenheiros, executivos, analistas e cientistas. Intelectuais estes que atuam em espaços decisórios que relativizam a soberania do Estado-Nação no que diz respeito às trocas internacionais, às barreiras alfandegárias, à livre concorrência, à concentração de capital (DREIFUSS, 1997; 2004), bem como à regionalização e integração da educação.

O MERCOSUL e a União Europeia representam as formas institucionais mais avançadas neste domínio, assumindo progressivamente um papel, cada vez mais, ativo na área das políticas sociais, em geral, e no domínio da educação, em particular (ANTUNES, 2005).

Temas como educação para o desenvolvimento econômico; produção e transferência de ciência e tecnologia; cultura, diversidade cultural e integração regional, entre outros, passam a ser tratados à revelia do público, assumindo o caráter de gestão supranacional no plano da grande política, com implicações na formulação de políticas e na ação governamental no âmbito da pequena política, em nível nacional ${ }^{5}$.

Contudo, o estado burguês supranacional só se sustenta pelos Estados-Nações que reúnam condições de inserir-se e enfrentar a concorrência no mercado mundial, particularmente nesta fase de crise estrutural do $\operatorname{capital}^{6}$,

autorização para funcionamento de instituições de ensino, cursos e sistemas de acreditação, bem como na celebração de convênios, o GATS entende que os serviços educacionais podem ser oferecidos nas modalidades de educação à distância e educação presencial, mantendo-se ou não a instituição sede no país receptor; por meio de programas de mobilidade estudantil; venda de "produtos" oriundos de pesquisas, além da oferta, por especialistas, de cursos, palestras, oficinas, etc.

5 Segundo Gramsci (2007, p. 21-22), a pequena política trata de questões parciais, conjunturais, e cotidianas das disputas entre frações políticas na arena do Estado. Já a grande política, denominada também de alta política, diz respeito à fundação ou à reorganização do Estado supranacional em torno da luta, seja pela destruição, seja pela defesa ou pela conservação da estrutura econômico-social organizada em nível internacional.

6 O capital passou por momentos de crises cíclicas chegando à crise estrutural. Diferentemente das crises cíclicas que abalam apenas uma das três dimensões fundamentais do capital (produção, consumo e circulação/ distribuição/realização), a crise estrutural afeta a totalidade do complexo social em todas as relações sejam na família, na escola, no mundo do trabalho e no Estado em sentido estrito (MÉSZÁROS, 2006). 
iniciada nos anos 1970, na qual sua administração vem mediada pelas políticas neoliberais.

Isto quer dizer que, a criação de organismos como a ONU, a OTAN, a UNES$\mathrm{CO}$, a OCDE, o Banco Mundial, o FMI, a OMC, bem como a integração de países em blocos político-econômicos, a exemplo do MERCOSUL e da União Europeia, não engendram o enfraquecimento do Estado ou o torna mínimo. Ao contrário. A tarefa política do Estado encontra-se, hoje mais do que nunca, na criação de medidas necessárias à reprodução social. O que implica transformá-lo em gerenciador do fundo público, isto é, agente de financiamento simultâneo da acumulação do capital e de reprodução da força de trabalho: financiando a acumulação do capital com gastos públicos na produção através de subsídios para agricultura, indústria, comércio, ciência e tecnologia, e financiando a reprodução da força de trabalho por meio de gastos sociais como educação, medicina socializada, previdência social, seguro-desemprego, vale-transporte, vale-alimentação, habitação, salário-família, etc. (OLIVEIRA, 1988; 2003).

Longe de comprovar a falência do Estado, a criação de organismos que atuam em escala global, bem como a de blocos político-econômicos regionais atesta o papel decisivo do poder político de Estado no processo de integração econômica, cujas estruturas econômicas e políticas intra-bloco e entre blocos são determinadas e determinantes pelas/das relações imperialismo e dependência ${ }^{7}$.

Os problemas que se levantam acima colocam a questão da relação trabalho e educação como parte da "necessidade sistêmica de o capital subjugar globalmente o trabalho [e a educação] por meio de toda e qualquer agência social" (MÉSZÁROS, 2003, p. 13), de modo a solver as contradições inerentes a sua essência: capital, trabalho e educação; produção, controle e consumo; produção e distribuição; competição e monopólio; competição, integração, regionalização e internacionalização.

Neste sentido, o processo de regionalização econômica por mediação do MERCOSUL, que abre caminho para a integração de outros setores, como o educacional, não pode ser negligenciado. E, tampouco, o processo de institucionalização birregional da educação superior (União Europeia e MERCO-

7 A especificidade da inserção competitiva do capitalismo brasileiro no mercado mundial, em sua nova fase, é elucidativa. Ela ocorre no âmbito da cooperação antagônica (MARINI, 2000; 1977), marcada, não apenas pela inserção regressiva da economia brasileira nos mercados regional e mundial, mas também pelo posicionamento ambivalente e contraditório que assume entre países periféricos e países de capitalismo central. Trata-se de um movimento, ao mesmo tempo, cooperativo e conflituoso. De um lado, o empresariado brasileiro demonstra sua subordinação consciente à integração imperialista, mantendo a dependência do padrão tecnológico controlado pelo capital central nos processos de desnacionalização e desindustrialização, enquanto valoriza o modelo agroexportador; de outro, mostra sua face autônoma, adotando, de modo agressivo, uma política de exportação de capitais particularmente para países da América Latina e África. 
SUL). Ambos os blocos visam a educação, em geral, e a educação superior, em particular, como fator de integração e peça-chave para a consolidação e projeção de seus Estados Membros e respectivo bloco no mercado mundial, afirmando seu papel precípuo na produção e transmissão do conhecimento científico-tecnológico orientado para o desenvolvimento econômico e a modernização.

O texto está estruturado da seguinte forma: primeiro expõe a gênese da criação do MERCOSUL e os sucessivos acordos com a União Europeia (UE), de modo a captar a dinâmica da política econômica regional na sua relação com a educação. Em seguida, evidencia os esforços de gestão supranacional dos assuntos educacionais, particularmente da educação superior, sob a ação do marco regulatório do $\mathrm{SEM}^{8}$. Desvela os mecanismos institucionais que, por mediação do Estado brasileiro, vêm propiciando a integração e regionalização da educação superior brasileira, particularmente por meio da avaliação e da mobilidade. Por fim, a título de primeiras aproximações, aponta para a institucionalização da educação em âmbito birregional (União Europeia e MERCOSUL).

\section{Da integração político-econômica à integração da educação}

Na América Latina, o entusiasmo em torno da integração regional, sob a égide do mercado comum, foi deslanchado pela Comissão Econômica para América Latina e Caribe (CEPAL) dos anos de 1960/70. Entretanto, foi com a criação do MERCOSUL que se intensificaram os processos de integração intrarregional, adotando a perspectiva do regionalismo aberto, segundo o qual zonas de livre-comércio e uniões aduaneiras são vistas como veículos à inserção no mercado mundial (TREIN; CAVALCANTI, 2007).

Tendo a UE como segundo maior investidor, a seguir aos Estados Unidos da América do Norte (EUA) e muito à frente do Japão, o MERCOSUL, instituído pelo Tratado de Assunção, de 1991, tem sua gênese em um contexto particular da trajetória dos países que o integram ${ }^{9}$ diante da necessidade de superar os efeitos negativos da denominada década perdida. Inseridos na "terceira onda de democratização" (HUNTINGTON, 1994, p. 30), Argentina e Brasil, líderes do bloco econômico, viam na criação do MERCOSUL uma estratégia de redução da vulnerabilidade das economias da região frente à hegemonia norte-americana.

8 O Setor Educacional do MERCOSUL é denominado, também, de MERCOSUL Educacional.

9 Na origem do MERCOSUL, os Estados Partes eram Argentina, Brasil, Paraguai e Uruguai, mais tarde juntam-se Venezuela (no ano de 2012) e Bolívia (que encontra-se em processo de adesão). O bloco possui o reforço de Estados Associados como Chile, Colômbia, Equador, Guiana e Suriname. 
Com o aprofundamento do processo de integração (neoliberal) regional e a maior necessidade, por parte do capital, de intensificar relações com os países da América Latina, o MERCOSUL incorpora os Estado Associados. Neste movimento, busca-se oferecer, de um lado, resistência às sucessivas negociações multilaterais em torno da Área de Livre Comércio das Américas (ALCA) tal como propunham os EUA: incluir na OMC o debate sobre os novos temas (investimentos, compras governamentais, políticas de concorrência) e o Trip Plus (requisitos de proteção dos direitos de propriedade intelectual, mais rigorosos do que aqueles exigidos pela $\mathrm{OMC}$ ). De outro, estreitar a cooperação com a UE que tem na integração extrarregional a perspectiva de formar uma divisão do trabalho birregional, de modo a favorecer novos fluxos de investimento, de circulação de produtos, serviços, pessoal qualificado e conhecimento, aumentando assim o fator de competitividade frente aos EUA e ao Japão.

Expressão dessa aproximação, no plano mais abrangente, são os sucessivos acordos de associação estratégica, firmados entre chefes de Estado e de Governo na Cúpula União Europeia e América Latina e Caribe (UE-ALC), a exemplo da Declaração de Rio de Janeiro, Brasil (1999); Declaração de Madrid, Espanha (2002); Declaração de Guadalajara, México (2004); Declaração de Viena, Áustria (2006); Declaração de Lima, Peru (2008); Declaração de Madrid, Espanha (2010); Declaração de Santiago, Chile (2013) ${ }^{10}$.

A plataforma de relações comerciais, investimentos e serviços das referidas Declarações vem acolhendo as propostas do setor empresarial, cujos líderes se reúnem em torno do Fórum Empresarial UE-ALC. Organizado nas trincheiras da Cúpula de Chefes de Estado e de Governo (UE-ALC), o fórum empresarial trata de temas como Aproximar os dois mundos através dos Negócios e da Cultura (2006); Inversão para o Bem-estar, o Desenvolvimento Sustentável e a Inclusão (2008); Investimentos para o crescimento econômico, a inclusão social e a sustentabilidade ambiental (2013) ${ }^{11}$.

10 Com a formalização da Cúpula da Comunidade dos Estados Latino-Americanos e Caribenhos (CELAC), no ano de 2011, como contraponto à Organização dos Estados Americanos (OEA) capitaneada pela hegemonia estadunidense, novos contornos geopolíticos vêm sendo construídos. Segundo portal do Planalto (BRASIL, 2012), o organismo tem como diretrizes principais, ampliar o diálogo político e realizar projetos de cooperação entre os 33 países da América Latina e Caribe, com o fito de definir a identidade regional calcada nas concepções latino-americanas e caribenhas comuns sobre integração e desenvolvimento. Contudo e a despeito da presença de chefes de governos marcadamente anti-imperialistas (Cuba, Equador, Bolívia, Uruguai, Venezuela), a CELAC, desde o ano de 2013, vem aliando-se com a União Europeia no processo de parceria birregional.

11 Do Fórum Empresarial UE-ALC participam, entre outros representantes do empresariado, o presidente de Business Europe, o presidente da Confederação Espanhola de Organizações Empresarial (CEOE), o Presidente da Confederação de Empresários Latino-Americanos a OEA, o presidente executivo da Organização Internacional de Empregadores (OIE). A Confederação Nacional da Indústria (CNI) possui relação estreita com o Fórum sem, no entanto, dele participar diretamente devido ao seu interesse de 
O Fórum Empresarial UE-ALC reconhece a importância do investimento em ciência, tecnologia e inovação $(\mathrm{C}, \mathrm{T} \& \mathrm{I})$ para o desenvolvimento econômico, considerando prioritária, para tanto, a criação de um Espaço Comum do Ensino Superior UE-ALC orientado para a mobilidade e a cooperação birregional, por mediação de programas de intercâmbios do conhecimento (estudantil e pesquisadores) e de trabalhadores qualificados.

Mais do que facilitar o intercâmbio do conhecimento (estudantil e pesquisadores) e de mobilidade de trabalhadores qualificados, busca-se promover um movimento sincrônico de sistemas de educação superior, entre blocos e intrabloco, com o fito de fortalecer um sistema de transferência e validação de créditos interinstitucional e internacional. Prevê-se instituir as condições necessárias para solidificar a interface entre pesquisa e inovação, facilitando a transferência e adaptação de tecnologia às empresas (UNIÃO EUROPÉIA, 2010).

Esta relação, em nível mais abrangente, entre UE-ALC não se descura do papel crucial do MERCOSUL na sua relação com a União Europeia. O projeto político estratégico do MERCOSUL, compartilhado pelos seus Estados (Partes e Associados), vem se consolidando em torno da União Aduaneira, da integração das cadeias produtivas e dos serviços ${ }^{12}$. Além deste aspecto, os Estados membros do MERCOSUL estão entre os beneficiários mais ativos da relação União Europeia e MERCOSUL em que se destacam o Acordo Quadro Interregional de Cooperação (1995); a Declaração Comum (2007a); Documento de Estratégia Regional [2007-2013] (2007b); a Declaração Comum (2008); o Comunicado Conjunto da Reunião Ministerial MERCOSUL-Troika UE (2009); e o Programa Regional para 2007-2013.

Busca-se com este arcabouço normativo birregional, estreitar laços em matéria de normas agro-alimentares e industriais, cooperação aduaneira, cooperação de propriedade intelectual, e cooperação empresarial, entre outras, com a finalidade de aumentar os fluxos de trocas comerciais, os investimentos, os projetos de cooperação industrial e a transferência de tecnologias; apoiar a modernização e diversificação industrial; favorecer a inovação industrial, por mediação de conferências, seminários técnicos, missões exploratórias, participação em feiras gerais e setoriais e em encontros empresariais; além do

aproximar-se, também, dos EUA, Canadá, México e Japão. Sua presença é marcante no(s) Encontro(s) Empresarial(is) UE-Brasil promovidos em âmbito nacional.

12 Novoa (2009) desvela o papel crucial do Banco Nacional de Desenvolvimento Econômico e Social (BNDES) no processo de liberalização e flexibilização comercial e alianças empresarias públicas privadas, com empresas de capital brasileiro e estrangeiro, no megaprojeto de reordenamento político-territorial, por meio da Integração da Infraestrutura Regional da América do Sul (IIRSA), o que não se faz sem os espaços de poder supranacionais. 
incentivo à iniciativa privada por meio do investimento colaborativo em $\mathrm{C}$, T\&I (MERCOSUL.UE, 2007b).

Daí a instrumentalização da educação seja pelo Estado seja pelos organismos supranacionais. Se o processo de internacionalização da economia, em níveis mundial e regional, inclui o comércio e fluxos internacionais de capitais; a entrada e saída de tecnologias incorporada tanto aos equipamentos quanto aos fluxos de informações e dados; a mobilidade de trabalhadores, toda esta dinâmica engendra formas de trabalho e de produção de conhecimento em redes, do que estudantes, docentes-pesquisadores, pessoal qualificado em pesquisa e desenvolvimento (P\&D) fazem parte. Nesta dinâmica, a educação, em geral, e a educação superior, passam a responder de modo imediato e mediato às dinâmicas do processo de internacionalização/regionalização da economia/ tecnologia, por mediação das políticas de C,T\&I, assumindo, assim, caráter internacionalizado/regionalizado.

Não é por acaso que os Programas-Quadros de investigação, seja em parceria com a União Europeia, seja na estrutura institucional do MERCOSUL, têm como estratégia o processo de internacionalização produtiva. A cooperação científica europeia com países do MERCOSUL assenta na participação destes países em projetos de pesquisa competitivos, segundo os sucessivos programas-quadro de investigação (PQ5 - 1998-2002; PQ6 - 2002-2006), tendo o Brasil e a Argentina participação significativa nesse processo, apresentando mais de cem projetos no período (MERCOSUL.UE, 2007b).

Este conjunto de relações sócio-institucionais pode ser encarado como uma das características da contraditória riqueza capitalista que pode facilmente se revelar se observamos seu conteúdo e forma social histórica. Neste sentido, examina-se a relação trabalho e educação que se vincula às relações capitalistas de produção, às relações de poder e de classe que acabam por determinar as modalidades de ajuste, seja por meio de reformas, seja através de modificações estruturais da sociedade.

\section{O processo de integração da educação superior brasileira}

O MERCOSUL, como projeto de integração político-econômica, além de basear-se na abertura aos mercados mundiais e no papel do Estado como regulador, normalizador, fiscalizador e catalisador das atividades econômicas, apóia-se na integração de outros setores como o cultural e o educacional, particularmente depois do Acordo Geral de Comércio de Serviços ${ }^{13}$ que inclui

13 Do inglês General Agreement on Trade in Services (Gats). 
a educação como atividade a ser comercializada. Trata-se de uma dinâmica de integração político-econômica que requer o desenvolvimento de políticas educacionais coerentes com as políticas de C,T\&I na perspectiva de "agregar valor à produção regional" (MERCOSUL.CMC, 2008b, p. 6-7).

Com a finalidade de construir instrumentos e canais que possam favorecer a circulação de capital, tecnologia, pessoal qualificado, informações e dados tanto em âmbito intrarregional (MERCOSUL) quanto birregional (União Europeia e MERCOSUL), que,

desde la constitución del MERCOSUR en 1991, los gobiernos que integran el pacto regional convinieron en atender una serie de temas colaterales al intercambio comercial, en particular los relativos al área de trabajo, justicia y educación. En efecto, el tema educativo fue puesto en relieve como un aspecto de importancia por los países miembros para llevar adelante el proceso de constitución comunitaria. En las reuniones previas al Tratado de Asunción y en la propia reunión fundacional, se fue definiendo una agenda de problemas y objetivos comunes que deberían atenderse por medio de la constitución de un proyecto específico para tal función: El Sector Educativo del MERCOSUR [...] Al mismo momento que el SEM intenta afianzarse como un instrumento para la construcción de nuevos espacios para el desarrollo económico, político y cultural fortalecedor de la identidad regional en un mundo globalizado, un importante debate en torno a la internacionalización de la educación superior viene llevándose a cabo desde la década de los 90's en el seno de organismos internacionales - UNESCO/OMC (FULQUET, 2006, p. 5).

Com efeito, do ato de criação do SEM, em 1991, no qual se firmou o Protocolo de Intenções ${ }^{14}$, passando pelos Planos de Ação executados ao longo das últimas duas décadas (1992/1994-1998 ${ }^{15}$; 1998-2000; 2001-2005; 2006-2010; 2011-2015), ao Termo de Cooperação Técnica MERCOSUL-UE para o período 2007-2013, vêm sendo criados mecanismos facilitadores do reconhecimento e da padronização/equiparação de estudos, da livre circulação de estudantes, do intercâmbio de docentes universitários e da formação de pessoal qualificado, graduados e pós-graduados, com a finalidade de promover a integração e a regionalização da educação superior ${ }^{16}$

14 Assinado em 13/12/1991, em Brasília, pelos Ministros da Educação da Argentina, do Brasil, do Paraguai e do Uruguai. A parte brasileira esteve representada por Antonio Teixeira de Souza Júnior, Ministro Interino da Educação no governo Collor de Mello.

15 Delineado para ser implementado entre 1992 e 1994, o $1^{\circ}$ Plano foi prorrogado até junho de 1998, devido às modificações introduzidas na estrutura institucional do MERCOSUL, pelo Tratado de Ouro Preto.

16 No que diz respeito ao processo de regionalização e integração da Educação Superior, os dois primeiros Planos fazem referência à criação do Espaço Comum Regional de Educação Superior, entretanto, a partir 
Entrementes, foram efetuadas alterações significativas na estrutura-institucional do bloco, particularmente na organização do SEM, com o objetivo de conceder maior eficiência e legitimidade aos planos de ação ${ }^{17}$. O organograma, a seguir, mostra a complexa estrutura do MERCOSUL Educacional, consoante o Plano de Ação do Setor Educacional do MERCOSUL 2011-2015.

Homens de seu tempo, os intelectuais que atuam no Setor Educacional do MERCOSUL afinam-se às orientações de ordem metodológica e financeira de organismos como o BM, a OCDE, a UNESCO e a CEPAL ${ }^{18}$, na elaboração dos Planos de Ação. Busca-se, por mediação dos referidos Planos, elevar a produtividade do trabalho, partindo do pressuposto de que educação e conhecimento são o eixo da transformação produtiva, da equidade social e da democratização política. Ao contribuir para a formação de uma consciência integradora, de aquisição de novos hábitos, atitudes e de competências laborais, a educação estaria formando, assim, o capital humano para ingressar na mobilidade, cujo movimento virtuoso é o da circulação de bens, serviços e capitais.

Essa concepção de educação atua no sistema educacional por meio de três vetores: o primeiro, de cima para baixo, vinculando as atividades do SEM aos planos nacionais de educação e aos processos de reforma dos Estados Partes, evidenciando, assim, um movimento de gestão supranacional dos assuntos educacionais. O segundo, na direção horizontal, atuando por meio da cooperação entre países do mesmo bloco ou de outros blocos regionais; o terceiro, dirigindo-se à construção do espaço comum de educação, de modo a favorecer o intercâmbio de experiências e práticas laborais, por meio da mobilidade de estudantes, acadêmicos e pesquisadores.

\section{Os mecanismos da integração e regionalização da educação}

Embora o foco deste artigo seja a educação superior, vale registrar que os acordos educacionais, no plano circunscrito ao MERCOSUL, não se limitam

do terceiro Plano Trienal (2001-2005), os ministros de educação dos Estados Partes do MERCOSUL e a Comissão Regional Coordenadora da Educação Superior (CRCES), a eles vinculada, passam a usar a expressão Espaço Educacional Comum, evidenciando a coordenação articulada das políticas de educação, em todos os níveis de ensino.

17 Entre outras modificações na organização do bloco, decorreram a transformação da Secretaria Administrativa em Secretaria Técnica, a criação da Comissão de Representantes Permanentes do MERCOSUL e de sua Presidência, a instalação do Tribunal Permanente de Revisão e do Tribunal Administrativo Laboral, o Fundo de Convergência Estrutural (FOCEM), e o estabelecimento do Parlamento do MERCOSUL.

18 Recentemente, a CEPAL afirmou que países periféricos não devem retroceder nas reformas neoliberais, mas, sim, retomá-las, implementado um conjunto de políticas econômicas - de longo prazo, com foco na crise iniciada em 2008, em escala em global -, nos setores produtivo, trabalhista, territorial e social, no que a educação, mais uma vez, cumpre papel decisivo como fator de desenvolvimento econômico e alavanca para reduzir a desigualdade social. Cf. CEPAL (2010). 


\section{Organograma do Setor Educacional do MERCOSUL ${ }^{19}$}

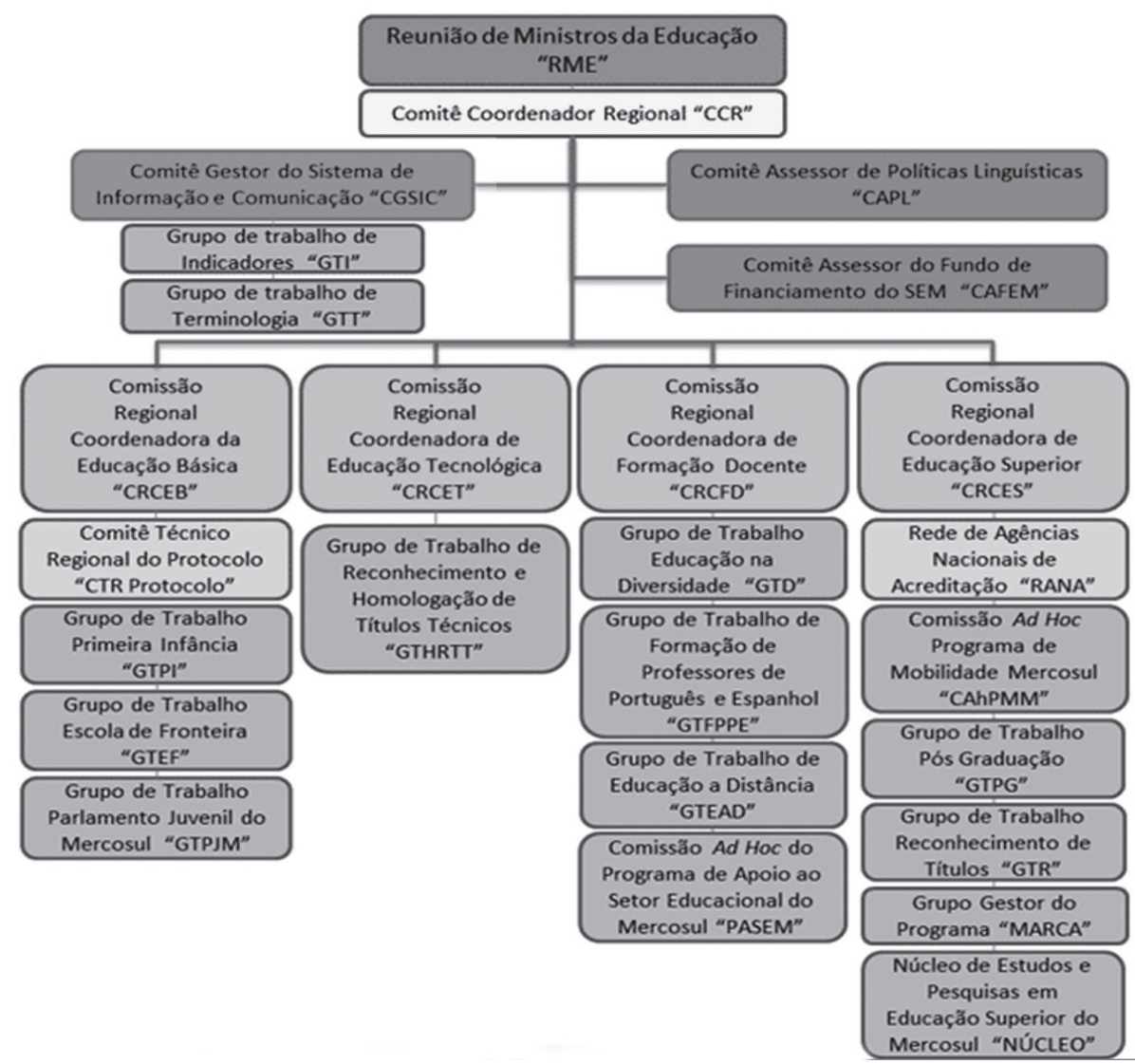

Fonte: MERCOSUL. Setor Educacional do Mercosul. Instâncias do Setor Educacional do MERCOSUL. Uy.: MERCOSUL, 2012a.

apenas a ela. A integração educacional inclui também a educação básica (ensino fundamental e médio), como bem evidenciam os Protocolo(s) sobre integração educativa e reconhecimento de certificados, título e estudos de nível primário e médio não técnico (MERCOSUL. CMC, 1994)²0; de integração educacional,

19 O SEM mantém vínculos com: Comunidade dos Estados Latino-Americanos e Caribenhos (CELAC); Comissão Econômica para a América Latina (CEPAL); Instituto de Avaliação e Acompanhamento das Metas Educacionais 2021 (IESME); Organização dos Estados Americanos (OEA); Organização dos Estados Iberoamericanos (OEI); Organização das Nações Unidas para a Educação, a Ciência e a Cultura (UNESCO); Sistema de Informação de Tendências Educacionais na América Latina (Siteal); União Europeia (EU); União de Nações Sul-Americanas (UNASUL).

20 No ano de 2010, foi firmado o Protocolo de Integração Educativa e Reconhecimento de Certificados, Títulos e Estudos de Nível Primário/Fundamenta/Básico e Médio/Secundário entre os Estados Partes 
revalidação de diplomas, certificados, títulos e de reconhecimento de estudos de nível médio técnico (MERCOSUL. UE, 1995); de Integração cultural do MERCOSUL (MERCOSUL.CMC, 1996), de modo a favorecer o enriquecimento e a difusão de expressões culturais entre os Estados Partes; além do Acordo de admissão de títulos certificados e diplomas para o exercício da docência no ensino do espanhol e do português como línguas estrangeiras nos Estados Partes $^{21}$. Este Acordo teve Parecer homologado pelo Conselho Nacional de Educação, do Ministério da Educação do Brasil (BRASIL.MEC 2004).

Nas origens do SEM, visava-se apenas o reconhecimento de títulos para as atividades acadêmicas e não para o exercício da profissão, como bem evidencia o Protocolo de Admissão de Títulos e Graus Universitários para o Exercício de Atividades Acadêmicas dos Países do MERCOSUL (MERCOSUL.SEM, 1997). Entretanto, no ano de 1999, o Protocolo é modificado pela Decisão no 04/99 e passa a oferecer a possibilidade de docentes brasileiros, argentinos, paraguaios e uruguaios exercerem atividades, em âmbito regional, de ensino e pesquisa em cursos de graduação e pós-graduação reconhecidos pelo MERCOSUL Educacional.

Os Estados Partes, por meio de seus organismos competentes, admitirão unicamente para o exercício de atividades de docência e pesquisa nas instituições de ensino superior no Brasil, nas universidades e institutos superiores no Paraguai, nas instituições universitárias na Argentina e no Uruguai, os títulos de graduação e pós-graduação reconhecidos e credenciados nos Estados Partes, segundo procedimentos e critérios a serem estabelecido para a implementação deste acordo (MERCOSUL.SEM, 1999) $)^{22}$.

Todas essas decisões dizem respeito à pedra angular da construção do Espaço educacional comum: a mobilidade e a avaliação. No nível da educação superior, a livre circulação de pesquisadores, docentes e estudantes é uma das metas que

do MERCOSUL e Estados Associados (Decisão n 21/10), que regulamenta a mobilidade estudantil e cria a comissão para atualizar a tabela de equivalência de estudos, segundo as reformas educacionais dos seguintes países: Argentina, Brasil, Paraguai, Uruguai, Bolívia, chile, colômbia, Equador e Venezuela. Decisão não vigente.

21 Todos os documentos citados encontram-se em Tratados, Protocolos y Acordos depositados en Paraguay. Disponível em http:/www.mercosur.int/innovaportal/v/5271/2/innova.front/tratados-protocolos-yacuerdos

22 No Brasil, a admissão/revalidação dos títulos de graduação e de pós-graduação stricto sensu (mestrado e doutorado), obtidos no exterior, não é automática, devendo ser solicitada a uma universidade reconhecida pelo MEC que conceda título equivalente. Do mesmo modo, qualquer atividade a ser exercida por estrangeiro, mesmo proveniente de países do MERCOSUL, sua diplomação ou certificação de curso de graduação ou pós-graduação depende de revalidação, na forma estabelecida pelo art. 48 da LDB e pela Resolução CNE/CES nº 01/2007. 
vem sendo perseguida pelo SEM desde o Compromisso de Brasília - Metas do Plano Trienal para o Ano 200023. A exemplo do que ocorre na União Europeia, com o Processo de Bolonha, a mobilidade estudantil no MERCOSUL se sucede por mediação do sistema de transferência de créditos.

Ainda que não tenha sido universalizado entre os cursos de graduação reconhecidos pelos Ministérios de Educação dos Estados Partes e Associados, o aproveitamento de estudos vem ocorrendo através do Programa MARCA ${ }^{24}$. Este Programa oferece, aos estudantes, a possibilidade de cursar um semestre acadêmico em universidades, cujos cursos de graduação foram acreditados conforme o Sistema ARCU-SUL ${ }^{25}$. Relativamente, a mobilidade estudantil e a transferência e validação de créditos interinstitucional e internacional vêm ocorrendo entre cursos da educação superior realizada no bloco regional do MERCOSUL ${ }^{26}$. Mais adiante, voltaremos ao tema do MARCA. Antes, porém, tratemos do processo de acreditação de cursos e da formação da cultura da avaliação.

Segundo o Portal do Ministério da Educação (MEC), acreditação é o resultado do processo de avaliação, por meio do qual é certificada a qualidade acadêmica dos cursos de graduação dos Estados Partes e Associados, segundo critérios de qualidade previamente aprovados no âmbito regional. Os diplomas pelos cursos acreditados levam um selo de qualidade do Setor Educacional do MERCOSUL.

Para o Ministério da Educação brasileira há uma diferença entre os processos de acreditação e de credenciamento. Este, realizado em nível nacional, se

23 Composto por três partes, o Compromisso de Brasília orienta os trabalhos do SEM: primeira, Termos de Referência para a Definição do Plano Trienal do Setor Educacional do MERCOSUL, 1998-2000; segunda, Plano Trienal 1998-2000 do Setor Educacional do MERCOSUL; e, terceira, Compromisso de Brasília: Metas do Plano Trienal para o Ano 2000. Assinaram o Documento os então ministros Paulo Renato Souza (Ministro da Educação do Brasil no governo FHC); Rafael Jacobo (Vice-Ministro de Educação do Paraguai); Antonio Guerra (Subsecretário de Educação e Cultura do Uruguai); Manuel García Solá (Vice-Ministro de Educação da Argentina). Pelos Estados associados assinou Tito Hoz de Vila Quiroga (Ministro de Educação, Cultura e Desporto da Bolívia).

24 Programa de Mobilidade Acadêmica Regional para os cursos acreditados pelo Sistema de Acreditação de Cursos de Graduação no MERCOSUL e Estados Associados.

25 Sistema de Acreditação de Cursos de Graduação no MERCOSUL e Estados Associados.

26 Como a exposição deste texto tem por base a análise de documentos emanados pelo MERCOSUL e pelo Estado brasileiro, não se logrou, até o momento, a possibilidade de proceder ao levantamento do número de estudantes brasileiros beneficiados pelo Programa MARCA, por ano, por curso e por universidade. Por se tratar de um fenômeno novo na reforma da educação superior, encontra-se carência de informações sobre o processo de mobilidade estudantil, em nível regional. Conforme informações do portal do MEC, pode-se afirmar apenas que participaram do Programa de Mobilidade Acadêmica Regional estudantes matriculados nas seguintes instituições: Universidade Federal de Viçosa, Universidade Estadual de Campinas, Universidade Estadual de Londrina, Universidade Federal do Rio de Janeiro, Universidade de Brasília Universidade Federal de Uberlândia, Universidade Federal de Campina Grande, Universidade Estadual Paulista (BRASIL.MEC, 2009b). 
refere ao processo de autorização de funcionamento da instituição de ensino superior brasileira, segundo a sua organização acadêmica: faculdade, centro universitário e universidade. Expirada a validade do credenciamento (três anos para faculdades e centros universitários; cinco anos para universidades) e após se submeter ao Sistema Nacional de Avaliação da Educação Superior (SINAES) ${ }^{27}$, a instituição de ensino solicita o seu recredenciamento, do que o reconhecimento e renovação de cursos fazem parte.

Ainda segundo o MEC, o processo de acreditação do MERCOSUL Educacional é de responsabilidade das agências nacionais de acreditação que, designadas pelos Ministros de Educação de cada Estado Parte ou Associado, atuam em nível nacional. Deste modo, uma agência nacional de acreditação acaba por se confundir com a comissão nacional de avaliação. No Brasil, de acordo com a Portaria MEC no 1734/2011, a Agência Nacional de Acreditação (ANA) é constituída pela Secretaria de Regulação e Supervisão da Educação Superior (SERES), Comissão Nacional de Avaliação da Educação Superior (CONAES) e Instituto Nacional de Estudos e Pesquisas Educacionais Anísio Teixeira (INEP). De sua parte, a(s) Agência(s) Nacional(is) de Acreditação integra(m) a Rede de Agências Nacionais de Acreditação do MERCOSUL (RANA).

Em outras palavras: as Agências Nacionais de Acreditação, órgãos executivos do Sistema ARCU-SUL, organizam-se numa Rede, denominada Rede de Agências Nacionais de Acreditação, que cria suas próprias regras de funcionamento e toma decisões por consenso em nível da política supranacional. Inserida na estrutura do Setor Educacional do MERCOSUL, a RANA ${ }^{28}$ responde diretamente à Comissão Regional Coordenadora de Educação Superior e à Reunião de Ministros de Educação, sendo responsável pelo Sistema de Acreditação de Cursos de Graduação no MERCOSUL e Estados Associados - ARCU-SUL ${ }^{29}$.

Leite e Genro (2012) apontam para a organização de agências de acreditação em redes como um fenômeno relativamente recente na América Latina e Caribe. Além da RANA, afirmam, outras redes de agências de acreditação estão em atuação no continente latino-americano e Caribe, a exemplo da Rede Ibero-americana para Acreditação da Qualidade da Educação Superior (RIACES),

27 Vinculado ao Instituto Nacional de Estudos e Pesquisas Educacionais Anísio Teixeira (INEP), o SINAES é coordenado pela Comissão Nacional de Avaliação da Educação Superior (CONAES).

28 Vale conferir sua posição no organograma acima.

29 O Sistema de Acreditação Regional de Cursos de Graduação do MERCOSUL (ARCU-SUL) veio substituir, no ano de 2008, o MEXA que, por sua vez, foi formulado, em 1998, no Memorando de Entendimento sobre a Implementação de um Mecanismo Experimental de Credenciamento de Cursos para o Reconhecimento de Títulos de Graduação Universitária nos países do MERCOSUL. Entretanto, somente mais tarde, foi implementado na vigência do Plano Estratégico 2001-2005. O MEXA vigorou entre os anos de 2003 e 2006, credenciando os então selecionados cursos de Agronomia, Engenharia e Medicina, bem como reconhecendo seus expedidos diplomas ((MERCOSUL.SEM, 1998b). 
que vem se projetando no cenário internacional por intermédio de associações de reitores e de universidades.

Para Dias Sobrinho (2008), existe uma tendência a substituir o reconhecimento pela acreditação, uma vez que esta última, valorizada internacionalmente, procede à avaliação tanto institucional quanto de cursos.

A cultura da avaliação, que hoje faz parte da realidade educacional brasileira, foi uma das linhas programáticas do Compromisso de Brasília (MERCOSUL. SEM, 1998a), coerentemente com o Protocolo de Intenções (MERCOSUL. SEM, 1991). Neste sentido, os ministros de educação alinhavaram as condições operativas para obter a comparabilidade e convergência dos sistemas nacionais por meio da criação de Agência Credenciadora Nacional, em todos os países membros, tornando possível, assim, a convergência das políticas educativas supranacional e nacional.

Os Ministros de Educação que assinaram o Plano Trienal 1998-2000 comprometeram-se, a "pressionar os sistemas educacionais para melhorar e controlar a qualidade da educação por eles oferecida a fim de assegurar a formação de competências (saberes, práticas e atitudes) equivalentes e facilmente credenciáveis, num espírito de integração regional" (MERCOSUL. SEM, 1998c, p. 4). Assinaram o referido Plano Trienal, Paulo Renato e Souza (Brasil), Rafael Jacobo (Paraguai), Antonio Guerra (Uruguai), Manoel Solá (Argentina), Tito Quiroga (Bolívia) e Maria Josefina Bianchi (Chile).

O Brasil entrou neste esforço a partir de 1995, de implantação de sistemas nacionais de avaliação e de indicadores educacionais, criando um eficiente sistema de informações que abrange todos os níveis e modalidades de ensino, da educação infantil à pós-graduação, numa clara diretriz de governo sobre a importância estratégica de se criar mecanismos de avaliação para o monitoramento dos sistemas de ensino [...], cooperação internacional, com os objetivos de adquirir conhecimento, compartilhar experiências e expor o Brasil a comparações com outros países (CASTRO, 2000).

Desde então, a Coordenação de Aperfeiçoamento de Pessoal de Nível Superior (CAPES) encarrega-se da avaliação da pós-graduação e recomendação de cursos, enquanto o INEP incumbe-se da graduação, sendo a regulação de atribuição da Secretaria de Educação Superior (SESu) e do Conselho Nacional de Educação (CNE).

Assim, a partir da Lei no 9131/1995 e da Lei no 9394/1996 (LDB), foram progressivamente implementados mecanismos de avaliação, com ênfase em resultados, produtividade, eficiência e, ainda, com controle do desempenho 
frente a um padrão estabelecido e prestação de contas: Exame Nacional de Cursos, realizado por concluintes de cursos de graduação; Questionário sobre condições socioeconômicas do aluno e suas opiniões sobre as condições de ensino do curso frequentado; Análise das Condições de Ensino; Avaliação das Condições de Oferta; Avaliação Institucional dos Centros Universitários. Estes instrumentos de avaliação foram incorporados ao SINAES, em vigor desde 2004, que possui instrumentos complementares (auto-avaliação, avaliação externa, Exame Nacional de Desempenho de Estudante).

Aqui cabe um parêntese. Tramita na câmara dos deputados, o Projeto de Lei 4372/12, do Executivo, que cria o Instituto Nacional de Supervisão e Avaliação da Educação Superior (INSAES), uma autarquia que será vinculada ao MEC, que assumirá a tarefa do Inep nos processos de avaliação, acreditação e supervisão dos cursos de graduação das instituições federais, privadas e beneficentes de ensino superior, no Brasil.

Alvo de contenda, o INSAES deverá aplicar penalidades e instrumentos previstos na legislação de modo a intervir nas IES. Entretanto, a criação do INSAES, ao que tudo indica, não elidirá as atribuições da CONAES e do INEP junto à RANA (BRASIL.MEC, 2013) fecha-se o parêntese.

Em nível regional, o processo de criação do sistema de credenciamento e reconhecimento de títulos avança, materializando-se em programas como, o MARCA e o ARCU-SUL, os quais o Brasil vem liderando muitas as ações, nos últimos mandatos de governo (2003-2104), pelo papel de destaque que assume na política de building blocks, bem como da responsabilidade do INEP frente à secretaria da RANA.

Não há, ainda, estatísticas sobre os processos de avaliação e acreditação que possam ser comparáveis regionalmente. Segundo o Plano de Ação do Setor Educacional do MERCOSUL 2011-2105, tais processos não seguem o mesmo ritmo em todos os países do bloco. Estima-se que aproximadamente 500 cursos de graduação foram acreditados ${ }^{30}$.

Coerentemente com o acordo celebrado entre a Comissão Regional de Educação Superior do MERCOSUL ${ }^{31}$ e o GATS (MERCOSUL.SEM, 2002),

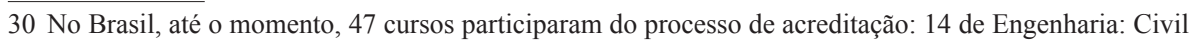
(UFRGS, UPF, UEM, UPG); Alimentos (UFV); de Materiais (UPG, UFRGS); Produção Mecânica (CU do IMT); Elétrica (USP, UFRGS, UFMG, UNESP, UFCG); Mecânica (UFU, UFRJ); Química ( PUC-RJ Unicamp; 17 de Agronomia (UnB, UFU, UPF, UEM, UniMontes, UEPG, UniOeste, , UNESP, UFED, UEL); 8 de Arquitetura (UPF, UFRGS, UniRitter, UniFUMEC, PUC-Pr, UniSinos, UFMG, UFRGN); 5 de Enfermagem (UnB, UniOeste, FAMENA, PUC-SP, UniRio); 3 de Medicina: FCMSCSP, UEL, UFSP); 5 de Medicina Veterinária (UnB, UFPr, UFF, UEL, PUC-MG). Cf Portal Arc-Sul, Disponível em http:// sistemaarcusul.mec.gov.br/arcusul/pages/pesquisaexterna/pesquisarCursoExterno.seam

31 É possível observar, no organograma acima, sua disposição e interrelação no interior do Setor Educacional do MERCOSUL. 
na perspectiva de liberalização progressiva dos serviços educacionais no nível de ensino superior, esses processos de avaliação e credenciamento da educação superior, que contam com apoio financeiro BID ${ }^{32}$, consideram, no mínimo, os seguintes aspectos: contexto institucional, recursos humanos, infra-estrutura e projeto acadêmico pautado na formação e avaliação por competências profissionais e ação investigativa. Aspectos estes, que no Brasil, vêm sendo perseguidos pela CONAES e INEP.

O ARCU-SUL, concebido como política de Estado, ao visar a formação de recursos humanos qualificados (MERCOSUL.CMC, 2008a), estabelece um vínculo estreito entre educação e desenvolvimento econômico do Estado, individualmente, e bloco regional a que pertence, tendo por base a ideologia da sociedade do conhecimento e da comunidade científica coesa, ao mesmo tempo em que contribui para regionalização da educação superior.

A coesão vem sendo construída por meio de uma estratégia de produção e organização do consenso, sutil, mas não menos importante. Ela é impulsionada por mediação dos Estados Partes do MERCOSUL e dos Estados Associados, que realizam o convite às instituições de educação superior a submeterem à acreditação os cursos que, previamente, são indicados, ao processo, pela Reunião de Ministros de Educação do MERCOSUL.

Para se candidatar ao Sistema ARCU-SUL a instituição interessada, por meio de seu coordenador de curso, com aprovação do Pró-Reitor de Graduação ou cargo equivalente, deve assinar um termo de Compromisso de Participação Voluntária no processo de Acreditação pelo Sistema ARCU-SUL (modelo em anexo) e o enviar por meio eletrônico à Coordenação do Sistema ARCU-SUL, para o endereço eletrônico: conaes.mercosul@mec.gov.br,no período de 01 a 30 de maio de 2009. Uma vez recebido o Compromisso de Participação Voluntária, a CONAES informará à Instituição candidata a data de realização da reunião técnica de orientação para auto-avaliação do curso nos padrões do Sistema ARCU-SUL. A reunião técnica de orientação deverá ocorrer em Brasília até no máximo 15 (quinze) dias após o prazo de recebimento do Compromisso de Participação Voluntária (BRASIL.MEC, 2009a).

No Brasil, atualmente, estão envolvidos no processo de acreditação pelo ARCU-SUL os cursos de Agronomia, Arquitetura, Enfermagem, Engenharia

32 A aproximação entre o Banco Interamericano de Desenvolvimento (BID) e o setor da educação superior do MERCOSUL se deu, no ano de 2006, por iniciativa do governo Lula da Silva. Segundo o Relatório (2005-2007) da Assessoria Internacional do Gabinete do Ministro da Educação do Brasil, o BID solicitou reapresentação do Projeto sobre o Mecanismo de Credenciamento de Cursos, no âmbito da convocatória do Programa de Bens Públicos Regionais. O projeto previa a transferência de recursos do BID no valor de cerca de US\$ 750 mil para o fortalecimento do programa de credenciamento (BRASIL.MEC, 2008). 
(nas modalidades Alimentos, Civil, Elétrica, Materiais, Mecânica, Produção e Química), Medicina, Odontologia e Medicina Veterinária. Segundo Sérgio Franco, então presidente da CONAES, no ano de 2007, o ARCU-SUL tem "como objetivo fomentar a qualificação da educação superior, certificando os cursos com um selo de padrão de qualidade como a certificação ISO 9000" (MAGALHAES, 2007).

Neste sentido, ainda que não obrigadas a submeterem os cursos ao processo de acreditação, as IES acabam por aderir ao processo. Garantem, assim, oficial e publicamente, a validez das titulações acadêmicas e habilitações profissionais, em escala regional, para o exercício da docência e atividades de pesquisa no âmbito de convênios ou tratados ou acordos bilaterais, multilaterais e regionais que venham a ser celebrados a esse respeito ${ }^{33}$.

Sempre associados ao MARCA, esses processos de avaliação e acreditação se articulam e ampliam no âmbito regional, tendo, a CAPES e a SESu, no Brasil, papel decisivo na execução do Programa. Este programa de mobilidade beneficia estudantes, docentes-pesquisadores e pessoal ocupante de cargos administrativos vinculados aos cursos acreditados pelo ARCU-SUL.

Para os discentes, o Programa oferta bolsas de estudos para intercâmbio, durante um semestre letivo, em instituição de outro Estado Parte ou Associado, com aproveitamento e reconhecimento de estudos, tanto na universidade de origem quanto na instituição de destino, respectivamente. Quanto ao corpo docente, oferece fomento para execução de projetos de pesquisa interinstitucionais, propiciando a cooperação regional de docentes-pesquisadores; e propicia a consecução dos objetivos de integração e regionalização da educação envolvendo gestores e coordenadores de instituições de ensino superior (MERCOSUL.SEM, 2007).

\section{A institucionalização da educação superior em âmbito birregional (UE-MERCOSUL): primeiras aproximações}

O processo de integração político-econômica regional, que acaba por integrar também a educação, não ocorre apenas como meio de o bloco oferecer resistência às sucessivas negociações multilaterais de ordem econômica stricto sensu. Ele abre espaço para uma relação de tipo cooperação antagônica ${ }^{34}$ entre blocos. Relação esta que engendra um conjunto de protocolos de comunicação,

33 Lembro que, anteriormente, citei a Decisão nº 04/99, do SEM/MERCOSUL que oferece a possibilidade de exercício de atividades docentes e nível regional.

34 Sobre a cooperação antagônica ver Marini (1977; 2000). 
informação e transmissão de dados, de transferência de tecnologias entre indústrias, de inovação industrial, bem como de cooperação institucional (gestão administrativa e pedagógica) e de formação científica e tecnológica de pessoal qualificado.

Robertson (2009) aponta para a institucionalização da educação superior nas relações interregionais, via Uniâo Europeia com o Processo de Bolonha. De fato, o Universitários MERCOSUL, um projeto de cooperação entre UE e MERCOSUL que veio apoiar o Programa de Mobilidade MERCOSUL em Educação Superior, bem evidencia o papel central que a educação ocupa nos processos de integração regional e na relação entre blocos.

Firmado no ano de 2008 e financiado em parte pela União Europeia, o Universitários MERCOSUL, coerentemente com os Planos do Setor Educacional do MERCOSUL 2006 - 2010 e 2011-2015, abarca universidades públicas e privadas vinculadas aos Ministérios de Educação da Argentina, Brasil, Paraguai e Uruguai, de modo a consolidar a criação do Espaço Comum do Ensino Superior, impulsionando e fortalecendo, assim, programas de mobilidade de estudantes, estagiários, docentes, pesquisadores, reitores, coordenadores de curso e outros profissionais da educação, de cursos ainda não acreditados pelo ARCU-SUL.

Neste sentido estão sendo executados dois programas, quais sejam, o Programa de Mobilidade do MERCOSUL (PMM) e o Programa de Apoio ao Setor Educacional do MERCOSUL (PASEM). O primeiro visa a que estudantes universitários dos países intra-MERCOSUL sejam selecionados como beneficiários de bolsas de estudo similares ao do MARCA. Mas, à diferença dos estudantes beneficiários do programa MARCA, o PMM destina-se aos jovens matriculados em cursos que não passaram pelo processo de credenciamento do sistema ARCU-SUL (MERCOSUL.SEM, 2012b).

A mobilidade ocorre através da participação em cursos, projetos de pesquisas e programas de extensão, garantindo o reconhecimento pleno das atividades desenvolvidas (ensino, pesquisa, extensão) na universidade de destino por parte das universidades de origem dos estudantes. No que diz respeito às atividades de ensino segue, ainda de forma tímida, o sistema de transferência de créditos a que me referi anteriormente.

Quanto ao PASEM, ele se desenvolve em torno do fortalecimento da formação docente (iniciação à docência, formação inicial em serviço, formação continuada em serviço, educação infantil, ensino de Ciências, ensino de Português e Espanhol, Uso das tecnologias da educação na formação docente, e gestão, implementação e avaliação de políticas de formação docente), cujas 
metas e objetivos foram estabelecidas no Plano Estratégico do SEM. O Programa vem sendo desenvolvido na Argentina, Brasil, Paraguai e Uruguai, sob a coordenação do Ministério de Educação da Argentina, que, desde o ano de 2012, se encontra em sua segunda fase de execução.

Toda essa dinâmica do SEM revela-se como um tema de estudo complexo, na medida em que, apesar de seus quase 25 anos de existência, é um fenômeno novo, silencioso e pouco estudado no Brasil.

Analisar as modificações que vêm ocorrendo na Educação Superior, no Brasil, à luz dos propósitos e concretizações do SEM, pode trazer contribuições em estudos baseados nas disputas de forças políticas e estratégias de organização administrativo-pedagógicas e de funcionamento e institucionalização da educação superior, em níveis nacional e regional.

\section{Considerações finais}

Conclui-se a análise sobre as recentes modificações ocorridas na educação superior brasileira à luz dos propósitos e concretizações do MERCOSUL Educacional retornando ao início deste texto, quando se aponta que temas como educação para o desenvolvimento econômico; produção e transferência de ciência e tecnologia; cultura, diversidade cultural e integração regional, entre outros, vem assumindo o caráter de gestão supranacional no plano da grande política, com implicações na formulação de políticas e na ação governamental no âmbito da pequena política, em nível nacional.

O MERCOSUL representa uma das formas institucionais mais avançadas no domínio dos assuntos educacionais mesmo que seja um processo de integração de cujas questões de ordem econômica e geopolíticas são predominantes e, ainda, que estudiosos na área das relações internacionais e alguns veículos de informação apontem para sua trajetória como um desenvolvimento vacilante, marcado por circunstâncias e determinações tanto da política macroeconômica quanto de pressões de setores empresarias internos (em nível nacional).

Concorda-se com Perrota (2014) quando afirma que a integração da educação, por mediação do MERCOSUL Educacional, avança de forma gradual e contínua. Desde a sua criação, o Setor Educacional do MERCOSUL vem estabelecendo um arcabouço normativo-institucional de modo a educação, em geral, e a educação superior, em particular, responder à dinâmica da internacionalização da economia e, de seu correlato, a internacionalização da tecnologia. A avaliação junto à mobilidade estudantil e de pessoal qualificado tornou-se vetor direcionador da reforma educativa em nível nacional, que vem sendo 
executada por meio de programas como o MARCA, o PASSEM, o PMM e o processo de credenciamento do sistema ARCU-SUL.

No século XIX, Marx e Engels (2004) já apontavam para a internacionalização do conhecimento como processo concreto, decorrente da natureza tendencial do capitalismo de se expandir globalmente em busca de novos mercados. A burguesia, afirmavam, engendra certo tipo de universalização da interdependência das nações na produção intelectual. A resposta da classe trabalhadora a este movimento burguês, do que, mais tarde, Gramsci (1976; 2007) observou como uma tentativa de construir uma internacional capitalista, só poderia ser a união dos trabalhadores de todos os países em torno da educação pública, gratuita de formação omnilateral. Isto é, ainda que a relação trabalho e educação seja mediação para o desenvolvimento sócio-econômico, político e cultural do ser social na direção da emancipação humana, ela não deve padecer interessada e imediatamente aos interesses econômicos mercadológicos.

Não se trata aqui, portanto, de ser contra os processos de regionalização e integração da educação, mas sim ter clareza do porquê deste movimento e valer-se de suas contradições, de modo a direcioná-la para os interesses universais da classe trabalhadora.

\section{Referências}

ANTUNES, Fátima. Governação global e diretrizes internacionais para a educação na União Européia: entrevista. Revista Perspectiva, Santa Catarina, v. 23, n. 2, p. 449-465, 2005.

BRASIL. Ministério da Educação. Conselho Nacional de Educação.

Conselho Pleno. Parecer $n^{0}$ 005/2004, de 6 de julho de 2004. Dispõe sobre o Acordo de Admissão de Títulos, Certificados e Diplomas para o Exercício da Docência do Espanhol e do Português como Línguas Estrangeiras nos Países do Mercosul. Brasília: MEC: CNE/CP, 2004.

BRASIL. Ministério da Educação. Comissão Nacional de Avaliação da Educação Superior. Convite aos cursos de agronomia e arquitetura de instituições de ensino superior brasileiras para participarem do processo de acreditação pelo Sistema ARCU-SUL. Brasília: MEC: CONAES, 2009a. 
BRASIL. Ministério da Educação. Programa de Mobilidade Acadêmica Regional em cursos Acreditados (MARCA). Relação de cursos universitários participantes do Programa Marca em 2009. Brasília: MEC, 2009b. Disponível em http://portal.mec.gov.br/marca. Acesso em: mar. 2014.

BRASIL. Ministério da Educação. Comissão Nacional de Avaliação da Educação Superior. Ponderações da CONAES referentes à implantação do PL 4.372/2012 (após aprovação pelo Congresso Brasileiro), aprovadas pela CONAES na $101^{\text {a }}$ reunião ordinária de 15 de outubro de 2013. Brasília: MEC: CONAES, 2013.

BRASIL. Ministério da Educação. Programa de Mobilidade Acadêmica Regional em cursos Acreditados (MARCA). Disponível em http://portal. mec.gov.br/marca. Acesso em: mar. 2014.

BRASIL. Ministério da Educação. Relatório 2005-2007, da Assessoria Internacional do Gabinete do Ministro da Educação do Brasil. Brasília: MEC, 2008. Disponível em: <http://portal.mec.gov.br/ai/arquivos/pdf/ relatorio2005_07.pdf $>$. Acesso em: julho de 2011.

CASTRO, Maria Helena Guimarães de. A participação do Brasil em estudos e avaliações educacionais comparados internacionais. In: BRASIL. Ministério das Relações Exteriores. Departamento Cultural, 2000. Textos do Brasil $n^{\circ} 7$ - Educação para um desenvolvimento humano e social no Brasil. Disponível em: <http://dc.itamaraty.gov.br/imagens-e-textos/revistatextos-do-brasil/portugues/edicao-numero-7>. Acesso em: abr. 2011.

COMISSÃO ECONÔMICA PARA AMÉRICA LATINA E CARIBE. O investimento estrangeiro direto na América Latina e Caribe. Nações Unidas: CEPAL, 2010. Disponível em: < http://www.eclac.cl/publicaciones/ xml/4/43304/2011-238_LIEP_2010-WEB_PORTUGUES.pdf >. Acesso em: maio 2011

DIAS SOBRINHO, José. Acreditação da educação superior. In: SEMINÁRIO INTERNACIONAL DE AVALIAÇÃO DA EDUCAÇÃO SUPERIOR, 2., 2008, Brasília. Anais... Brasília: MEC/CONAES, 2008. Disponível em: <http://portal.mec.gov.br/index.php?option=com_content\&vi ew $=$ article $\& \mathrm{id}=15305 \&$ Itemid $=1075>$. Acesso em: outubro de 2010 
DREIFUSS, René. Época das perplexidades: mundialização, globalização e planetarização: novos desafios. 2. ed. Petrópolis: RJ: Vozes, 1997.

DREIFUSS, René. Transformações: matrizes do século XXI. Petrópolis: RJ: Vozes, 2004.

FULQUET, Gaston. A. El Proyecto Educativo para el MERCOSUR y los Debates en torno a la Internacionalización de la Educación Superior. Buenos Aires, Ar.: CAEI, 2006.

GRAMSCI, Antonio. Escritos políticos [1910- 1919]. Lisboa: Seara Nova, 1976.

GRAMSCI, Antonio. Cadernos do cárcere. 3. ed. Rio de Janeiro:

Civilização Brasileira, 2007. (v. 3. Maquiavel; Notas sobre o Estado e a política).

HUNTINGTON, Samuel. A terceira onda: a democratização no final do século XX. Rio Janeiro: Ática, 1994.

LEITE, Denise; GENRO, Maria Elly Herz, Avaliação e internacionalização da educação superior: Quo vadis América Latina? Avaliação, Campinas; Sorocaba, v. 17, n. 3, p. 763-785, nov. 2012. Disponível em: <http://www.scielo.br/scielo.php?script=sci_arttext\&pid=S141440772012000300009\&lng=pt\&nrm=iso $>$. Acesso em: jan. 2015.

MAGALHÃES, Gláucia. Selos de qualidade para cursos do Mercosul. Ministério da Educação/Notícias, Brasília, 2007. Disponível em: <http:// portal.mec.gov.br/index.php?option $=$ com_content\&task=view\&id=8009>. Acesso em: fev. 2011.

MARX, Karl; ENGELS, Freidrich. Manifesto do Partido Comunista. São Paulo: Martin Claret, 2004.

MARINI, Ruy Mauro. La acumulación capitalista mundial y el subimperialismo. Cuadernos Políticos, Cidade do México, MX. n. 12, abr./jun. 1977. Disponível em <http://www.marini-escritos.unam.mx/004 articulos_marini.html $>$. Acesso em junho de 2009.

MARINI, Ruy Mauro. Dialética da dependência. Petrópolis, RJ: Vozes, 2000 . 
MERCOSUL. Conselho do Mercado Comum. Decisão n 04/94. Protocolo sobre Integração Educativa e Reconhecimento de Certificados, Títulos e Estudos de Nível Primário e Médio Não Técnico. Montevideo, Uy.: MERCOSUL. CMC, 1994.

MERCOSUL. Conselho do Mercado Comum. Decisão n 07/95. Protocolo de Integração Educativa e Revalidação de Diplomas, Certificados, Títulos e Reconhecimento e Estudos de Nível Médio Técnico. Montevideo, Uy.: MERCOSUL. CMC, 1995.

MERCOSUL. Conselho do Mercado Comum. Decisão no 11/96. Protocolo de Integração Cultural do MERCOSUL. Montevideo, Uy.: MERCOSUL. CMC, 1996.

MERCOSUL. Conselho do Mercado Comum. Decisão no 17/2008. Acordo sobre a criação e a implementação de um sistema de credenciamento de cursos de graduação para o reconhecimento regional da qualidade acadêmica dos respectivos diplomas no MERCOSUL e Estados Associados. Montevideo, Uy: MERCOSUL. CMC, 2008a.

MERCOSUL. Conselho do Mercado Comum. Programa-Quadro de Ciência, Tecnologia e Inovação do MERCOSUL, período 2008-2012, de 30/06/2008. Montevideo, Uy.: MERCOSUL. CMC, 2008 b.

MERCOSUL. Setor Educacional do Mercosul. Protocolo de Intenções, de 13/12/1991. Montevideo, Uy.: MERCOSUL. SEM, 1991. Disponível em: Disponível em < http:/www.sic.inep.gov.br/pt/documentos/cat_view/98documentos-e-referencias/45-acordos--acuerdos--agreements/96-acordosde-ministros--acuerdos-de-ministros--ministers-agreements $>$ Acesso em fevereiro de 2011.

MERCOSUL. Setor Educacional do Mercosul. Decisão n0 03/1997. Protocolo de Admissão de Títulos y Graus Universitários para o Exercício de Atividades Acadêmicas dos Países do MERCOSUL. Montevideo, Uy: MERCOSUL. SEM, 1997.

MERCOSUL. Setor Educacional do Mercosul. Compromisso de Brasília. Montevideo, Uy.: MERCOSUL. SEM, 1998a.

MERCOSUL. Setor Educacional do Mercosul. Memorando de Entendimento sobre a implementação de um mecanismo experimental 
de credenciamento de cursos para o reconhecimento de títulos de graduação universitária nos países do MERCOSUL (MEXA), de 19/06/1998. Montevideo, Uy.: MERCOSUL. SEM, 1998 b.

MERCOSUL. Setor Educacional do Mercosul. Decisão n¹3/1998. Plano Trienal e Metas do Setor Educacional. Montevideo, Uy: MERCOSUL. SEM, 1998c.

MERCOSUL. Setor Educacional do Mercosul. Decisão n0 04/1999. Protocolo de Admissão de Títulos y Graus Universitários para o Exercício de Atividades Acadêmicas dos Países do MERCOSUL. Montevideo, Uy.: MERCOSUL. SEM, 1999.

MERCOSUL. Setor Educacional do Mercosul. Ata no 2 da Reunião de Ministros de Educação. Montevideo, Uy.: MERCOSUL.SEM, 2000.

MERCOSUL. Setor Educacional do Mercosul. Plano Estratégico 20012005. Montevideo, Uy.: MERCOSUL. SEM, 2001.

MERCOSUL. Setor Educacional do Mercosul. Plano de Ação 2006-2010. Montevideo, Uy.: MERCOSUL. SEM, 2006.

MERCOSUL. Setor Educacional do Mercosul. ProMARCA. Montevideo, Uy.: MERCOSUL. SEM, 2007.

MERCOSUL. Setor Educacional do Mercosul. Decisão n 21/2010. Protocolo de Integração Educativa e Reconhecimento de Certificados, Títulos e Estudos de Nível Primário/Fundamenta/Básico e Médio/Secundário entre os Estados Partes do MERCOSUL e Estados Associados. Montevideo, Uy: MERCOSUL. SEM, 2010. Disponível em: <http://www.mercosur. int $/ \mathrm{t}$ _ligaenmarco.jsp? contentid $=4823 \&$ site $=1 \&$ channel $=$ secretaria $>$. Acesso: ago. 2011.

MERCOSUL. Setor Educacional do Mercosul. Plano de Ação 2011-2015. Montevideo, Uy.: MERCOSUL. SEM, 2011.

MERCOSUL. Setor Educacional do Mercosul. Instâncias do Setor Educacional do MERCOSUL. Uy.: MERCOSUL. SEM, 2012a. Disponível em: <http://edu.mercosur.int/pt-BR/mercosul-educacional/instancias.html $>$. Acesso em: nov. 2014. 
MERCOSUL. Setor Educacional do Mercosul. PMM - Programa de Mobilidade MERCOSUL/Fase Piloto. Montevideo, Uy.: MERCOSUL. SEM, 2012b.

MERCOSUL. Setor Educacional do Mercosul. Comissão Regional de Educação Superior. El Acuerdo General de Comercio de Servicios y la Educación. Vinculación con el MERCOSUR. In: ATA DA VI REUNIÃO DA COMISSÃO REGIONAL COORDENADORA DE EDUCAÇÃO SUPERIOR. Montevideo, Uy.: MERCOSUL. SEM. CRES, 2002.

MERCOSUL-UNIÃO EUROPÉIA. Acordo Quadro Interregional de Cooperação entre a Comunidade Européia e o Mercado Comum Sul, de 15/12/1995. Montevideo, Uy.: MERCOSUL. UE, 1995.

MERCOSUl-UNIÃO EUROPÉIA. Declaração Comum MERCOSULUnião Européia, de 17/12/2007. Montevideo, Uy.: MERCOSUL. UE, 2007a.

MERCOSUL-UNIÃO EUROPÉIA. Documento de Estratégia Regional 2007-2013. Montevideo, Uy.: MERCOSUL. UE, $2007 \mathrm{~b}$.

MERCOSUl-UNiÃO EUROPÉIA. Declaração Comum MERCOSULTROIKA EU, de 17/05/2008. Montevideo, Uy.: MERCOSUL. UE, 2008. MERCOSUL-UNIÃO EUROPÉIA. Comunicado Conjunto da Reunião Ministerial MERCOSUL-TROIKA UE, de 14/07/2009. Montevideo, Uy.: MERCOSUL. UE, 2009.

MÉSZÁROS, István. O século XXI: socialismo ou barbárie?. São Paulo: Boitempo, 2003.

MÉSZÁROS, István. Para além do capital. 1. ed. São Paulo: Boitempo, 2006.

NOVOA, Luis Fernando. O Brasil e seu "desbordamento": o papel central do BNDES na expansão das empresas transnacionais brasileiras na América do Sul. In: INTITUTO ROSA LUXEMBURG STITUNG et al (Org.). Empresas transnacionais brasileira na América Latina: um debate necessário. São Paulo: Expressão popular, 2009. p. 188-204.

OLIVEIRA, Francisco. O direitos do anti-valor: a economia política da hegemonia imperfeita. Petrópolis, RJ: Vozes, 1988. 
OLIVEIRA, Francisco. Crítica à razão dualista. O ornitorrinco. São Paulo: Boitempo, 2003.

PERROTA, Daniela. El regionalismo de la educación superior en el MERCOSUR como vector de internacionalización: un acercamiento desde la política regional de acreditación. Revista Latinoamericana de educación comparada. Buenos Aires, Ar: SAECE, v. 5, n. 5, p. 68-92, 2014.

ROBERTSON, Susan. O processo de Bolonha da Europa torna-se global: modelo, mercado, mobilidade, força intelectual ou estratégia para construção do Estado? Revista Brasileira de Educação, Rio de Janeiro: ANPEd, v. 14. n. 42, set./dez. 2009.

SILVEIRA, Zuleide Simas da. Concepções de educação tecnológica na reforma da educação superior: finalidades, continuidades, e rupturas estudo comparado Brasil e Portugal (1995-2010). Niterói, 2011. 445f. Tese (Doutorado em Educação) - Faculdade de Educação, Universidade Federal Fluminense, Niterói, 2011.

TREIN, Franklin; CAVALCANTI, Flávia Guerra. Uma análise crítica do acordo de associação estratégica entre a União Européia e a América Latina e o Caribe - A Cúpula de Viena. Revista Brasileira de Política Internacional, Brasília, v. 50, n. 1, p. 66-85, 2007.

UNIÃO EUROPEIA. Declaração de Viena: Quarta cimeira UE-ALC. Viena, Áustria: UE, 2006.

UNIÃO EUROPEIA. Declaração de Madrid: sexta Cimeira UE-ALC. Madrid, Espanha: UE, 2010.

Zuleide S. Silveira - Universidade Federal Fluminense Niterói | RJ | Brasil. Contato: zuleidesilveira@gmail.com

Artigo recebido em 10 de abril de 2015 e aprovado em 2 de dezembro de 2015. 
